\title{
New dextrin-vinylacrylate hydrogel: Studies on protein diffusion and release
}

\author{
Joana M. Carvalho ${ }^{\text {, }}$ Manuel A. Coimbra ${ }^{\text {b }}$, Francisco M. Gama ${ }^{\mathrm{a}, *}$ \\ ${ }^{a}$ IBB, Institute for Biotechnology and Bioengineering, Universidade do Minho, Campus de Gualtar, 4710-057 Braga, Portugal \\ ${ }^{\mathrm{b}}$ Departamento de Química, Universidade de Aveiro, 3810-193 Aveiro, Portugal
}

\section{A R T I C L E I N F O}

\section{Article history:}

Received 6 May 2008

Received in revised form 11 July 2008

Accepted 31 July 2008

Available online 9 August 2008

\section{Keywords:}

Dextrin

Drug release

Hydrogel

\begin{abstract}
A B S T R A C T
New dextrin hydrogels with degrees of substitution (DS) from ca. 10\% (DS 10) to 70\% (DS 70) were prepared by radical polymerization of aqueous solutions of vinylacrylate (VA)-derivatized dextrin. A preliminary analysis on the potential of these hydrogels for the controlled release of bioactive molecules was carried out. The protein (bovine serum albumin) diffusion coefficients on the hydrogels were calculated using the lag-time analysis. Values in range $10^{-7} \mathrm{~cm}^{2} / \mathrm{s}$ were obtained for DS 20 and DS 40 and a smaller value of $10^{-8} \mathrm{~cm}^{2} / \mathrm{s}$ arised upon DS increasing to $70 \%$, revealing the dependence of the diffusivity on the crosslinking density. The release of BSA from dextrin-VA hydrogels, in the presence of amyloglucosidase was shown to be mainly dependent on the diffusion and, to a smaller extent, on the degradation kinetics. The protein release can be tailored from days to months by varying the DS.
\end{abstract}

(c) 2008 Elsevier Ltd. All rights reserved.

\section{Introduction}

Biodegradable hydrogels are useful for a variety of medical applications (Dordick, Linhardt, \& Rethwisch, 1994; Han, Krochta, Kurth, \& Hsieh, 2000; Park \& Park, 1996). In general, hydrogels have a good biocompatibility and the soft rubbery consistence resemble natural tissues, allowing for a favourable controlled interaction with living systems (Vyavahare \& Kohn, 1994). Hydrogels may be used in the field of tissue engineering, as scaffolds to support and promote tissue regeneration and also as attractive systems for the controlled release of pharmaceutically active molecules (Kane, Tompkins, Yarmush, \& Burke, 1996; McCulloch \& Shalaby, 1998; Peppas, 1996; Peppas, Bures, Leobandung, \& Ichikawa, 2000). A drug delivery vehicle positioned in the proximity of the site of disease or injury can release the drug in the desired location, this way reducing the side effects that usually result from systemic administration. Additionally, depending on the crosslinking density, the hydrogels structure can restrict the diffusion of macromolecules, being able to deliver the therapeutic agent over extended periods of time. Indeed, improving in the patient compliance and extension of product life are major advantages of the drug delivery systems (Hubbell, 1995; Ratner, 2002). Ideal systems for drug delivery are degradable, permeable, porous and capable of maintaining a desired shape. In previous work, we have described a new dextrin based hydrogel, which could possibly match these properties (Carvalho, Gonçalves, Gil, \& Gama, 2007). Dextrin is a glucose containing polymer linked by $\alpha(1 \rightarrow 4)$ D-glucose units, having the same general formula as starch, but smaller and less complex.

\footnotetext{
* Corresponding author. Tel.: +351253604400.

E-mail address: fmgama@deb.uminho.pt (F.M. Gama).
}

In this study, we aim at evaluating the diffusion of two different molecules in the hydrogel matrixes, glucose and a model protein, bovine serum albumin (BSA). This will allow achieving a second goal, to evaluate the potential of the hydrogels as controlled release systems. For these purposes, the enzyme amyloglucosidase was used to modulate the release of proteins entrapped in the hydrogel. Thus, the degradation rate of the network may be controlled through the crosslink density of the hydrogels and the amount of enzyme present.

\section{Materials and methods}

\subsection{Materials}

Dextrin - Koldex 60 starch was a generous gift from Tate \& Lyle (Decatur, IL, USA). Vinyl acrylate (VA) was from Aldrich, $N, N, N^{\prime}, N^{\prime}-$ tetramethylenethylenediamine (TEMED), ammonium persulfate (APS) and Protein Assay were purchased from BioRad, dimethylsulfoxide (DMSO) and acetone were from Applichem and polyethyleneglicol (PEG $200 \mathrm{~g} / \mathrm{mol}$ ) was obtained from Riedel-d Haën. DMSO was dried with $0.4 \mathrm{~nm}$ molecular sieves at least overnight before use. BSA was from Sigma $\left(M_{\mathrm{w}}=67 \mathrm{kDa}\right)$. Regenerated cellulose tubular membranes with 3500 molecular weight cutoff (MWCO) were obtained from Membrane Filtration Products (Seguin, USA).

\subsection{Carbohydrate analysis}

Dextrin sugars were released by $1 \mathrm{M}$ sulfuric acid hydrolysis at $100{ }^{\circ} \mathrm{C}$ for $2.5 \mathrm{~h}$ and analysed as their alditol acetates by gas 
chromatography using a Carlo Erba 6000 with a split injector (split ratio 1:60) and a flame ionisation detector as described by Mafra et al. (2001). For determination of the linkage glycosidic composition, the dextrin sample was activated with powdered $\mathrm{NaOH}$ in dry dimethylsuphoxide and methylated with $\mathrm{CH}_{3} \mathrm{I}$ (Ciucanu \& Kerek, 1984). The methylated material was dissolved in dichloromethane:water $(1: 1, v / v)$, and the organic phase was recovered, washed several times with water, evaporated and freeze dried. The methylated polysaccharides were hydrolyzed with $2 \mathrm{M}$ TFA at $121^{\circ} \mathrm{C}$ for $1 \mathrm{~h}$, reduced by $\mathrm{NaBD}_{4}$ and acetylated in the presence of acetic anhydride and 1-methylimidazole. The partially methylated alditol acetates were analysed by GC-MS using an OV-1 capillary column as described by Cardoso, Ferreira, Mafra, Silva, and Coimbra (2007). Triplicates were made of all analyses.

\subsection{Preparation of dextrin-VA hydrogels}

Dextrin-VA monomers were synthesized from dextrin in DMSO in the presence of different amounts of vinyl acrylate. The transesterification reaction was carried out at $50^{\circ} \mathrm{C}$ for $72 \mathrm{~h}$. The degree of acrylate substitution (DS) was determined by proton nuclear resonance spectroscopy $\left({ }^{1} \mathrm{H}\right.$ NMR) in $\mathrm{D}_{2} \mathrm{O}$ as previously described (Carvalho et al., 2007). Briefly, ${ }^{1} \mathrm{H}$ NMR spectra were recorded in $\mathrm{D}_{2} \mathrm{O}(10 \mathrm{mg}$ in $1 \mathrm{~mL}$ ) and DS was calculated using Eq. (1):

DS $\%=\frac{x}{y} \times \frac{7}{3} \times 100$

where, in the NMR spectra, $x$ is the sum of the peak intensities corresponding to the protons from vinyl group ( $\delta$ in the range of 6.00$7.00 \mathrm{ppm})$ and $y$ is the sum of the peak intensities of all dextrin protons ( $\delta$ in the range of $0.00-6.00 \mathrm{ppm}$ ), excluding the water peak ( $\delta$ around $4.80 \mathrm{ppm}$ ) (Fig. 1). The hydrogel slabs with different DS (from ca. $10 \%$ to $70 \%$ ) were prepared by radical polymerization of aqueous solution of dextrin-VA. These solutions were prepared by dissolving dextrin-VA (300 or $400 \mathrm{mg}$ ) in buffer $(900 \mu \mathrm{L}$ ) (phosphate buffer $0.2 \mathrm{M}, \mathrm{pH} 8.0$ with $0.02 \%$ sodium azide) and bubbling with nitrogen for $2 \mathrm{~min}$. For the release experiments, before gelation, a BSA solution (in phosphate buffer) was added yielding a final concentration of $2 \mathrm{~g} / \mathrm{L}$. The gelation reactions were initiated by adding $90 \mu \mathrm{L}$ APS ( $80 \mathrm{mg} / \mathrm{mL}$ in phosphate buffer) and $90 \mu \mathrm{L}$ TEMED $(13.6 \%(\mathrm{v} / \mathrm{v})$ in water, $\mathrm{pH}$ adjusted to 8.0 with $\mathrm{HCl})$ and allowed to occur for $30 \mathrm{~min}$ at room temperature. For the preparation of dextrin-VA/amyloglucosidase (AMG) hydrogels, different amounts of enzyme solution (diluted to $10 \mathrm{U} / \mathrm{mL}$ in phosphate buffer) was added to the dextrin-VA solution before the addition of the gelation reagents, as described above.

\subsection{SEM analysis}

The internal and external structure of the hydrogels was analysed by SEM. Samples were either flash-freeze with liquid nitrogen or frozen at $-80^{\circ} \mathrm{C}$. Freeze-dried samples were gold sputter coated (SC 502 Golden Sputter, Fison instruments). All micrographs were taken using an S 360 Scanning Electron Microscope (Leica, Cambridge).

\subsection{Release experiments}

After polymerization, dextrin-VA hydrogels (with DS ranging from $20 \%$ to $70 \%$ ), with or without AMG, were transferred to individual containers. To maximize the area for free diffusion, a perforated polypropylene support was placed at $5 \mathrm{~mm}$ from the bottom of the containers. The hydrogels were placed on the supports, submerged with $30 \mathrm{~mL}$ of PBS, stored at $37^{\circ} \mathrm{C}$ and gently shaken at 100 strokes per minute. Samples $(100 \mu \mathrm{L})$ were taken at regular intervals and replaced by fresh buffer. The protein concentration in the samples was measured by using the BioRad protein assay (microassay procedure).

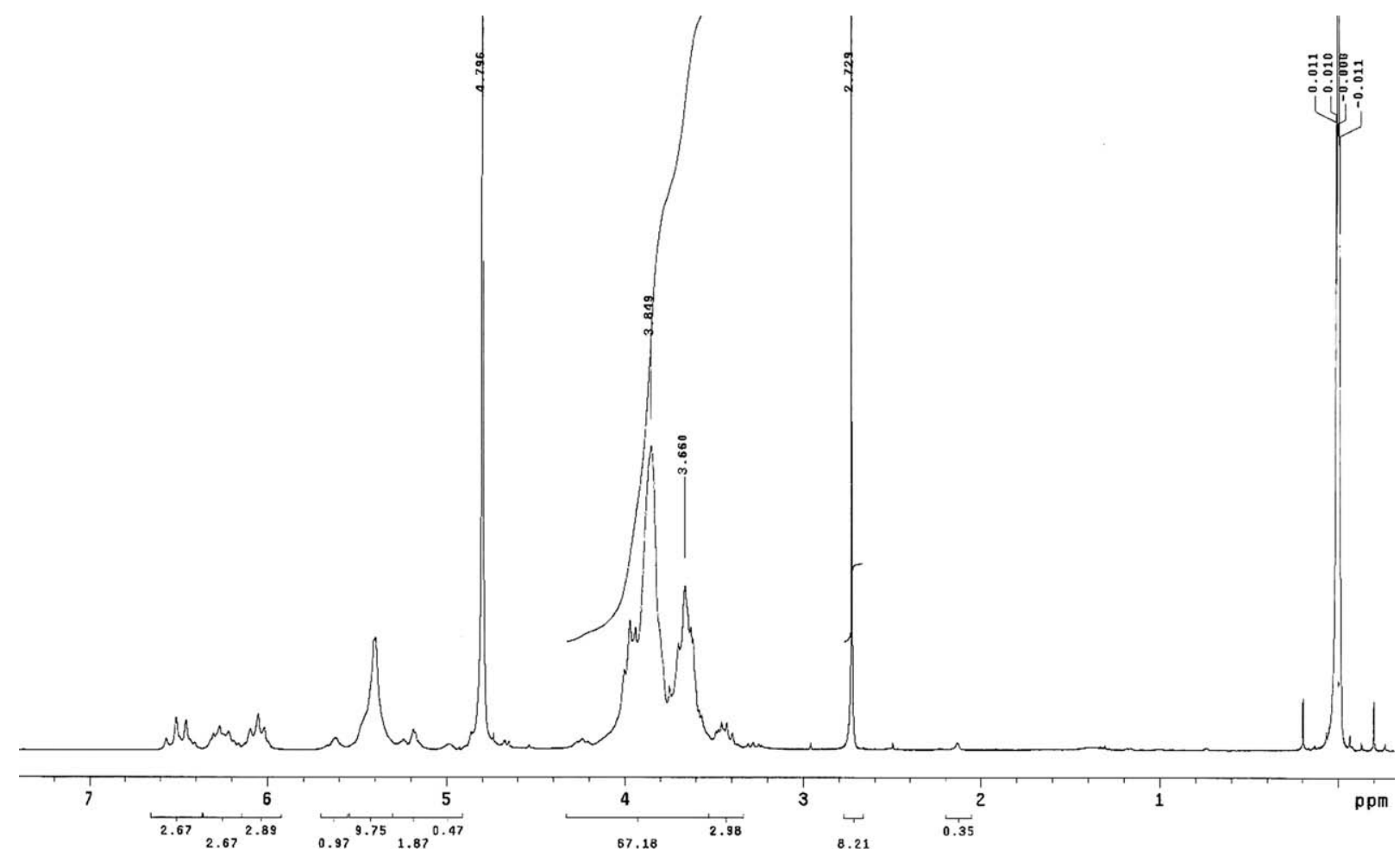

Fig. 1. ${ }^{1} \mathrm{H}$ NMR spectra of dextrin-VA in $\mathrm{D}_{2} \mathrm{O}$. $\mathrm{DS}=20 \%$. 


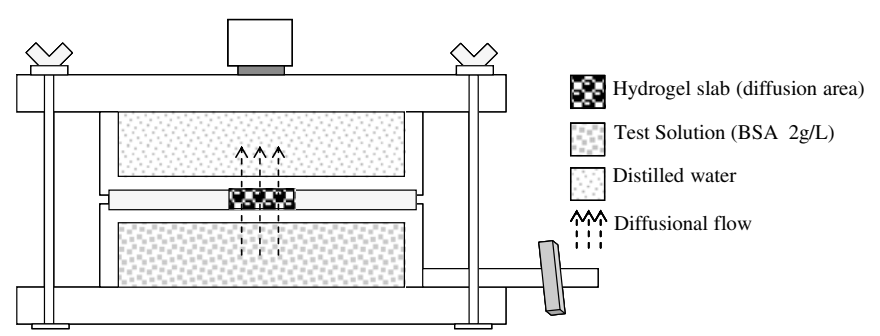

Fig. 2. Diagram of diffusion chamber (lateral view).

\subsection{Diffusivity experiments}

The diffusion cell is a modification of Teixeira, Mota, and Venâncio (1994) (Fig. 2). It is made of Perspex and consists of two chambers of $60 \mathrm{~mL}$, divided by a Perspex plate, in which the hydrogel ( $\varnothing$ $20 \mathrm{~mm}$; thickness of $0.5 \mathrm{~mm}$ ) is inserted. The whole structure is held together with screws. The Perspex plate is supported by a squared mesh and sealed with O-rings. Agitation was obtained using magnetically driven bars in both chambers.

For the diffusivity experiments, hydrogels with different DS (20, 40 and 70) were evaluated and the diffusion coefficients of BSA and glucose were calculated. Samples were collected at regular time intervals and replaced with distilled water. For the BSA assay, protein concentration was measured by using the BioRad protein assay (microassay procedure) and in the glucose assay, the soluble sugars were determined using the dinitrosalicylic acid (DNS) method. Concentration of glucose or BSA in the lower chamber was 100 or $20 \mathrm{~g} / \mathrm{L}$, respectively. The diffusion coefficients were calculated using lag-time analysis (Teixeira et al., 1994).

$Q_{\mathrm{ts}}=\frac{A D C_{1}}{l}\left(t_{\mathrm{s}}-\frac{l^{2}}{6 D}\right)$

where $Q$ is the total amount of solute transferred through the membrane $(\mathrm{g}), A$ the area $\left(3.14 \mathrm{~cm}^{2}\right), D$ the diffusion coefficient $\left(\mathrm{cm}^{2} / \mathrm{s}\right), C$ the concentration $\left(\mathrm{g} / \mathrm{cm}^{3}\right), l$ the membrane thickness $(0.5 \mathrm{~cm})$ and $t$ the time (s). The intercept of the linear part of the curve obtained by plotting $Q v$ s. time is the so called "lag time", $t_{\mathrm{s}}$, Solving the equation for $t=t_{\mathrm{s}}$ (the corresponding $Q_{\mathrm{ts}}=0$ ), allows the calculation of $D$. At least three independent assays were performed for each experiment.

\section{Results and discussion}

\subsection{Dextrin characterization}

The dextrin used to produce the hydrogel was only composed by glucose. Methylation analysis showed the presence of liner (85.3\%), non-reducing terminal (11.2\%) and branched (3.5\%)
Table 1

Glycosidic-linkage analysis of the dextrin used to prepare the hydrogel

\begin{tabular}{lc}
\hline Linkage & Relative abundance \\
\hline Terminal-Glcp & 11.2 \\
$(1 \rightarrow 4)-G l c p$ & 85.3 \\
$(1 \rightarrow 4,6)$-Glcp & 3.5 \\
Average degree of polymerization & 13 \\
\% Branching points & 3.5 \\
\hline
\end{tabular}

residues (Table 1). The proportion of terminal residues was three times higher than the proportion of branched residues. In a large molecular weight amylopectin molecule, the amount of terminal residues tends to be similar to the amount of branched residues. However, the shorter the molecule the higher the proportion of terminal residues in relation to the branched ones. In this sample, by the proportion of 3:1 it can be inferred the presence of linear structures (1 terminal and no branching residues) and structures with one branching point ( 2 terminals to 1 branching residue) in similar amounts (Table 1 and Fig. 3). By the difference between the abundance of the estimated terminal residues and those correspondent to the abundance of the branched residues, the amount of terminal residues in the main backbone can be estimated as 7.7\%. Taking this into account, the average degree of polymerization of the dextrins can be estimated by the sum of the abundance of all residues (100\%) divided by the abundance of terminal residues in the main backbone/7.7\%), that is, the dextrin had an average degree of polymerization of 13 glucose residues where one in each two molecules is a branched structure (Fig. 3).

\subsection{Diffusivity experiments}

The release of an active agent from a polymeric network consists on the diffusion of the agent through the bulk of the polymer (Amsden, 1998, 1999). Depending on the hydrogel network reticulation, the effective release of entrapped material may be controlled by the erosion/degradation of the polymer or by the mass transfer properties (Amsden, 1998; Kanjickal \& Lopina, 2004). To optimize the release characteristics of dextrin-VA hydrogels, a fundamental understanding of the diffusivity mechanism of biomacromolecules through the matrix is required.

The diffusion coefficient is affected by the molecular size of the solute and the characteristics of the polymer network, such as the crosslinking density, capable of affecting diffusivity to a large extent. Fig. 4 shows the different diffusion behavior of BSA (67 kDa) and glucose. After a lag-phase, the total amount of solute transferred through the hydrogel is proportional to the time. The diffusivity coefficients were determined using hydrogels with different DS, ranging from $20 \%$ to $70 \%$ (Table 2 ). The diffusion coefficient of
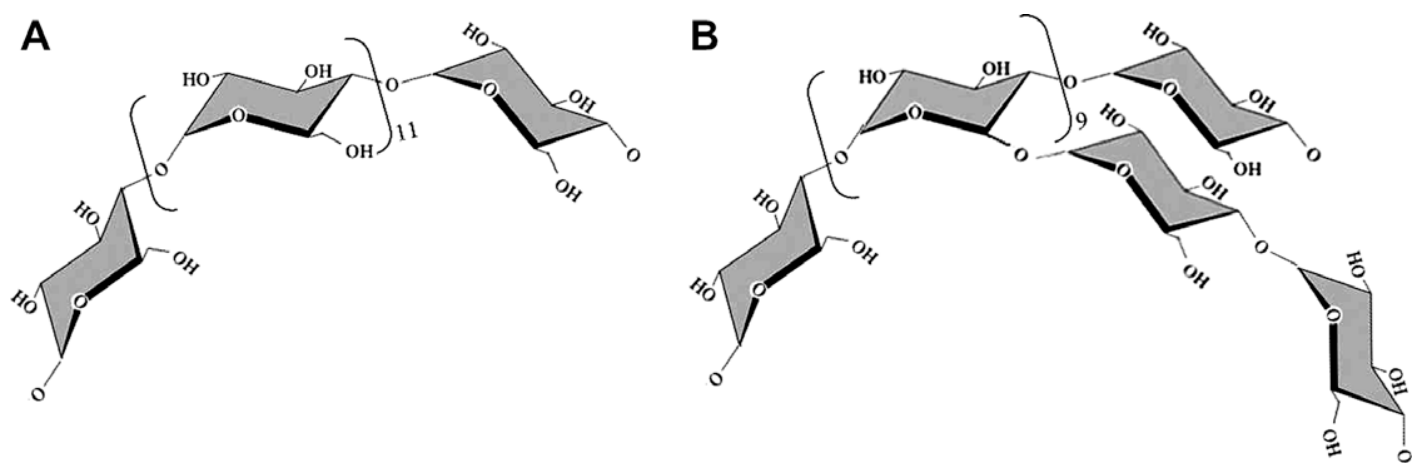

Fig. 3. Structure representative of the dextrin molecules used to form dextrin-VA hydrogels. (A) Linear structure. (B) Branched structure. 


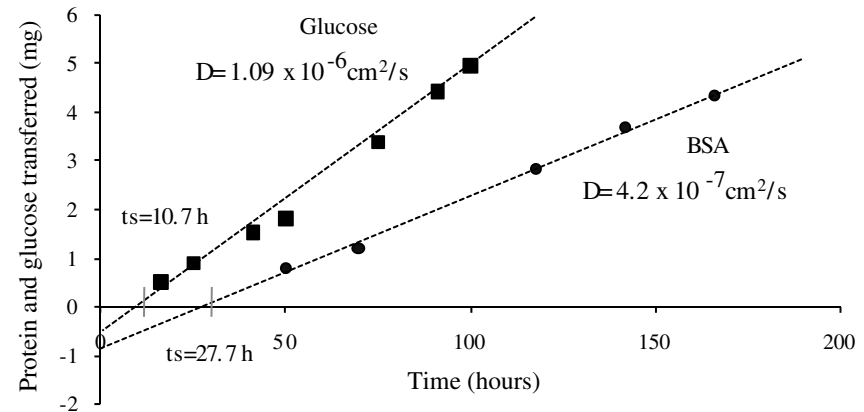

Fig. 4. Protein and glucose transferred through the membrane (DS $=20 \%$ ), vs. time, in the diffusivity experiments.

Table 2

Diffusivity coefficients of BSA and glucose for different hydrogel reticulation degrees and hydrogel mass loss values after 20 days

\begin{tabular}{llll}
\hline Hydrogel & \multicolumn{2}{l}{ Diffusivity coefficient $\left(\mathrm{cm}^{2} / \mathrm{s}\right)$} & \multirow{2}{*}{$\begin{array}{l}\text { Hydrogel mass loss (after } \\
\text { 20 days }(\%))\end{array}$} \\
\cline { 2 - 3 } & BSA & Glucose & \\
\hline 20 & $4.2 \pm 1.6 \times 10^{-7}$ & $1.1 \pm 0.7 \times 10^{-6}$ & 18.3 \\
40 & $1.5 \pm 1.2 \times 10^{-7}$ & $8.7 \pm 1.1 \times 10^{-7}$ & 15.8 \\
70 & $*$ & ND & 12.1 \\
\hline
\end{tabular}

ND, non-determined; $*$, no diffusion of BSA was detected after 80 days, implying a reduction of the diffusion coefficient by at least one order of magnitude.

BSA on the DS 20 hydrogel was $4.2 \pm 1.6 \times 10^{-7} \mathrm{~cm}^{2} / \mathrm{s}$. This value is only slightly lower than the one obtained by Lévesque, Lima, and Shoicheta (2005), for BSA diffusivity in water $\left(5.9 \times 10^{-7} \mathrm{~cm}^{2} / \mathrm{s}\right)$ and in the order of magnitude of the value obtained with
Dex-MA hydrogels $\left(3.1 \pm 0.2 \times 10^{-7} \mathrm{~cm}^{2} / \mathrm{s}\right)$. The diffusivity in water and in the hydrogel is thus in the same range, suggesting that these matrices probably have continuous water and polymer phases with interconnected pores. In fact, SEM analysis of threedimensional hydrogel slabs revealed a highly porous structure (Fig. 5). Hydrogels with lower DS (10\% and 20\%) exhibit irregular pores, in the size range $20-70 \mu \mathrm{m}$. However, we were able to alter the pore morphology by raising the DS up to ca. 70\%, thereby obtaining a material with much lower porosity. The diffusion coefficient obtained with a DS 40 hydrogel was $1.5 \pm 1.2 \times 10^{-7} \mathrm{~cm}^{2} / \mathrm{s}$. As expected, increasing the DS reduces the mobility of the biomolecules through the matrix. For a DS 70, a smooth surface is observed by SEM (Fig. 5) and large pores, and consequently interconnectivity, are no longer observed. As a matter of fact, a diffusion assay with a gel with DS 70, revealed no diffusion of BSA through the gel after approximately 80 days, implying a reduction of the diffusion coefficient by at least one order of magnitude. The ability to change the DS, thereby altering the crosslinking density and the whole structure of the network, allows modulating the diffusivity across the networks.

Finally, diffusion coefficients of $1.09 \pm 0.7 \times 10^{-6}$ and $8.7 \pm$ $1.1 \times 10^{-7} \mathrm{~cm}^{2} / \mathrm{s}$ were obtained for glucose, using hydrogels with DS of $20 \%$ and $40 \%$, respectively. These values are comparable to the one obtained by Ramos, Carvalho, and Gama (2006) for the diffusion of glucose in chitosan-dextrin-VA hydrogels and, as expected, higher than that those obtained for BSA.

\subsection{Release experiments}

For most biomedical applications, namely in drug delivery, hydrogels that degrade in clinically relevant time-scales are favoured over non-degradable ones. In addition to spontaneously degradable hydrogels, enzymatic degradation is also an interesting
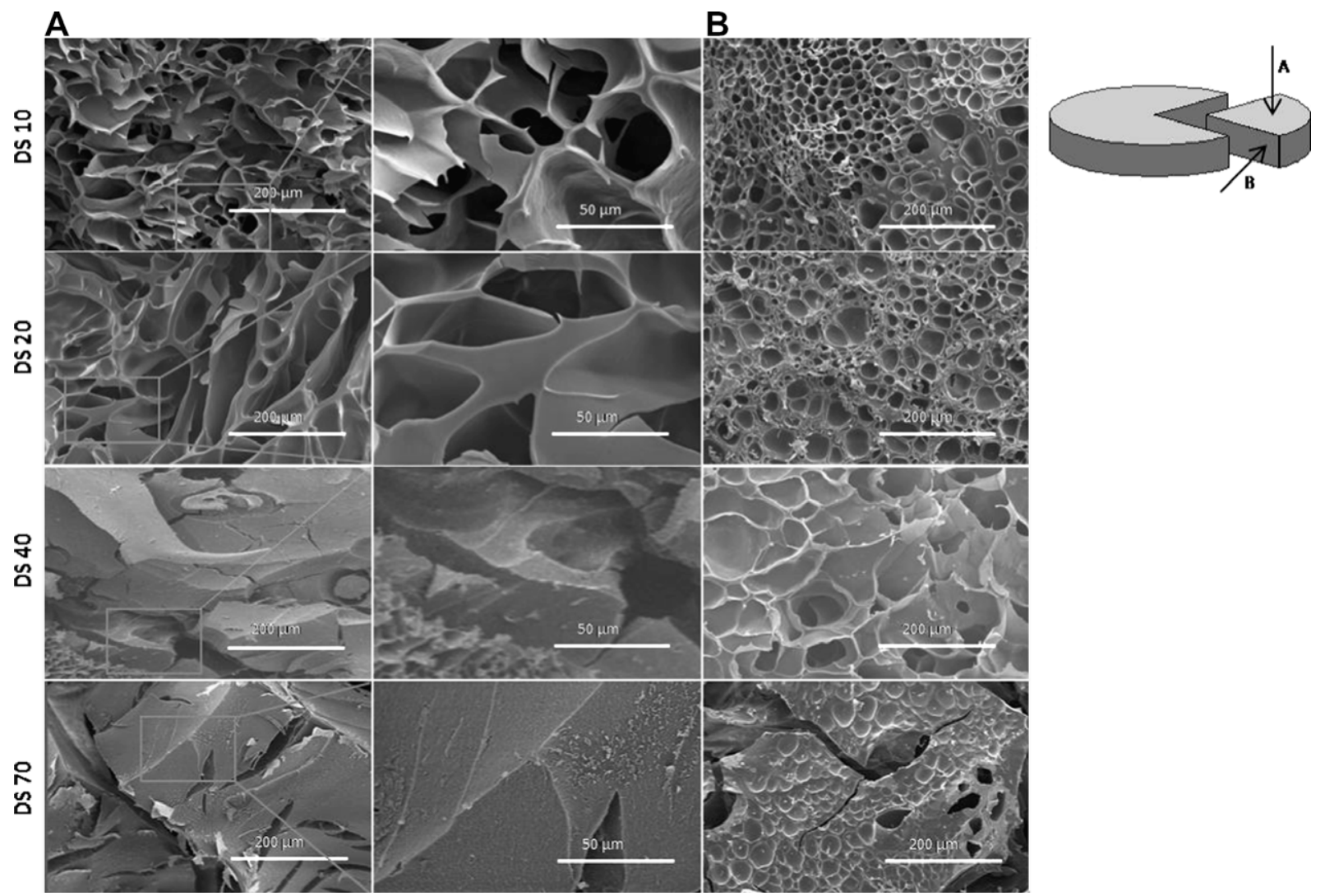

Fig. 5. SEM micrographs of hydrogel inner (A) and outer (B) surfaces with different DS, ranging from $10 \%$ to $70 \%$. 


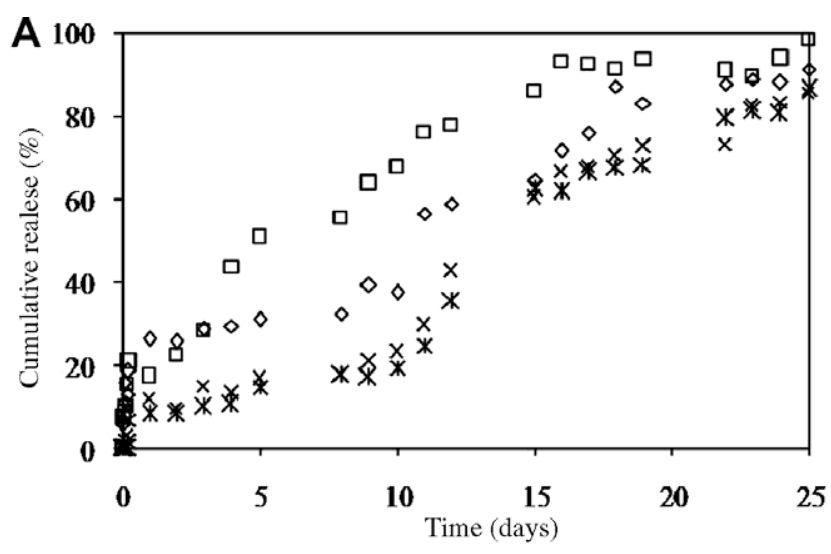

$\triangle$ Hydrogel w/ $800 \mu \mathrm{L}$ AMG

$\square$ Hydrogel w/ $400 \mu \mathrm{L}$ AMG

$\diamond$ Hydrogel w/ $200 \mu \mathrm{L}$ AMG

$\times$ Hydrogel w/ $40 \mu \mathrm{L}$ AMG

* Hydrogelw/o AMG
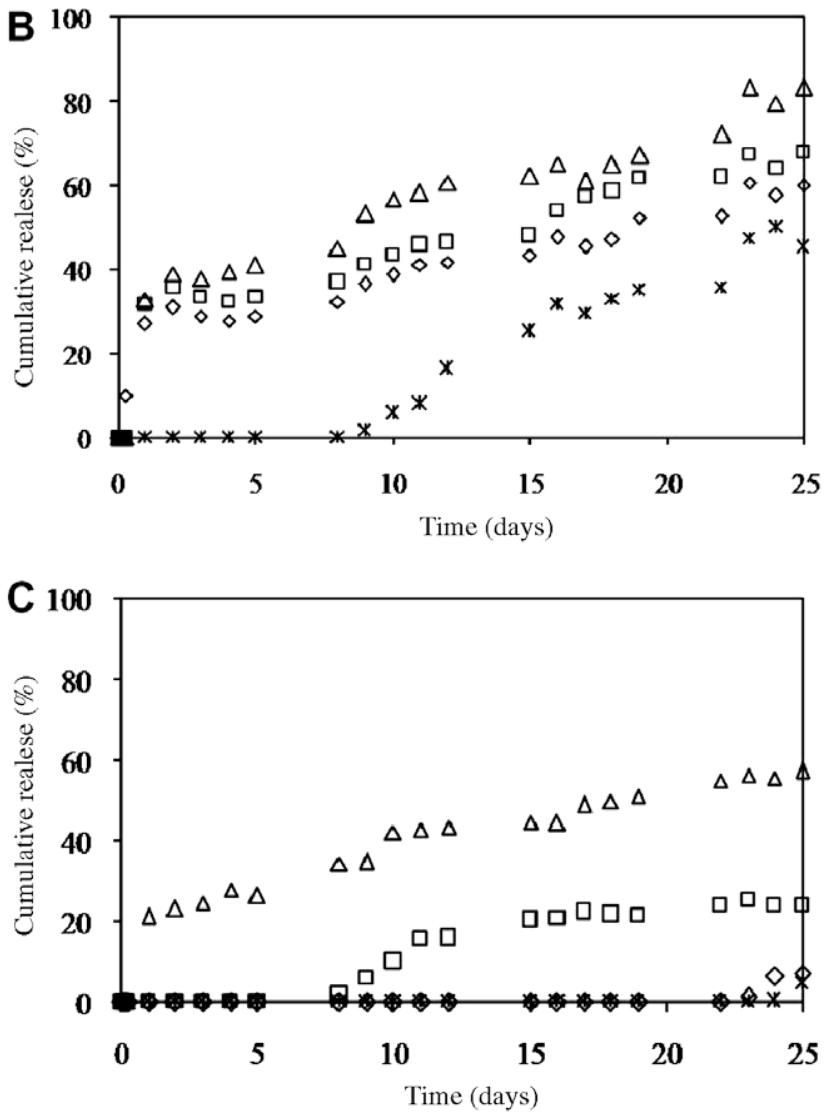

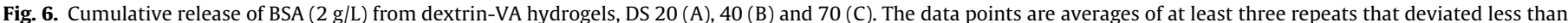
$5 \%$ of the total amount of protein in the hydrogels.

solution to obtain optimal degradation profiles, which result in proper rates of drug release (Mason, Metters, Bowman, \& Anseth, 2001; Okano \& Kikuchi, 2002; Rice, Sanchez-Adams, \& Anseth, 2006).

The release of BSA from dextrin-VA hydrogels was studied. The enzyme AMG was added to the dextrin-VA solutions before gelation, to analyse the effect of the enzymatic hydrolysis on the model protein release. Fig. 6 illustrates the cumulative protein release in the different assays. For the DS 20 hydrogel (Fig. 6A), a two stage release of protein is observed in all hydrogel samples, the rate slowing down through the time course of the experiment. In the initial incubation period (from 0 to $6 \mathrm{~h}$ ), only a small amount of BSA was released from all samples, corresponding to between $10 \%$ and $25 \%$ of the total amount of protein in the hydrogels. After approximately 20 days, most of the protein was effectively released from the gel, in all assays.

As it is well known, diffusion might not be the only factor determining the delivery rate, degradation playing also a critical role in determining overall release profiles. Degradation of crosslinks increases the mesh size of the gel, allowing for diffusion to be facilitated. Thus, the release of a molecule entrapped in a hydrogel network is controlled by (1) the diffusion through the matrix or (2) by hydrolysis of the network crosslinks, followed by an erosion process with mass loss (Amsden, 1999; Dijk-Wolthuis, Hoogeboom, van Steenbergen, Tsang, \& Hennink, 1997). While either diffusion or dissolution can be the predominant factor for a specific type of polymer, in most cases, the release kinetics is a result of a combination of these two mechanisms (Efentakis \& Buckton, 
2002; Lee, 1981; Sujja-areevath, Munday, Cox, \& Khan, 1998; Tahara, Yamamoto, \& Nishihata, 1995).

As can be seen in Table 1, after 20 days of incubation, for DS 20 , only approximately $20 \%$ of the hydrogel had undergone solubilization, according to dry weight measurements. Such mass loss reflects the release of non-reticulated material, since no significant degradation take place in the absence of the enzyme. As a matter of fact, the incubation of the hydrogel in water for up to 3 months did not lead to further mass release. Diffusion, rather than the enzymatic degradation, is the governing factor for the release in these hydrogels (DS20). Indeed, all of the protein is released even in the case where no AMG is used, which again shows that the protein is able to freely diffuse in the hydrogel network. The presence of increasing amounts of enzyme leads to higher BSA release rate, an effect that may be classified as moderate. As a matter of fact, as shown in the previous section, the protein diffusion in this hydrogel compares with the diffusion in water, hence the moderate effect observed in the presence of AMG.

As can also be seen in Fig. 6, for higher DS values the total amount released from degrading hydrogels (i.e. with AMG) was always much larger compared with the control (without enzyme), a process that seems to occur in an enzyme concentration-dependent manner. These results reveal that the presence of the enzyme, by hastening the degradation of the hydrogels, significantly affect the release rate (Fig. 6B and C). As can be seen, namely for the DS 70 hydrogel sample, in the absence of the enzyme, almost no release is detected, showing that, contrarily to the DS 20 gel, in which the release is mostly diffusional, for hydrogels with a rather high DS, the release behavior is driven by the enzyme concentration. In these cases, the higher crosslinking density prevents the free diffusion of the molecules. The network mesh is tighter, with subsequent reduced mobility. Likewise, the enzymatic cleavage of polymer chains raises the degradation process, reducing the time-scale of the slow natural bulk erosion, being thereby responsible for the control of the release rate.

These results show that the control of DS and of enzyme concentration allow for the establishment of release systems, controlled over different ranges of time, from days (low DS, higher enzyme) to months (higher DS, no enzyme). As reported by Meyvis, Smedt, Stubbe, Hennink, and Demeester (2001) with dextran-MA hydrogels, more recently by Vlugt-Wensink et al. (2006) and confirmed with our diffusivity results, an increase in DS of the hydrogel, thereby increasing the crosslinking density is an expeditious method to lengthen the duration of protein delivery. Taken together, all these variables can provide a versatile method of fine tuning the protein release rate.

\section{Conclusions}

The BSA release from the dextrin-VA hydrogel with DS 20 is mainly controlled by the diffusion rate. For hydrogels with higher DS, the enzymatic hydrolysis/erosion governs the release rate. By using hydrogels with different DS and enzyme concentration, it is possible to control the release rate from days to weeks, or even months.

\section{Acknowledgements}

This research was supported by Fundação para a Ciência e a Tecnologia under Grant SFRH/BD/17482/2004 and FUNCARB POCTI/BIO/45356/2002.

\section{References}

Amsden, B. (1998). Solute diffusion within hydrogels: Mechanisms and models. Macromolecules, 31, 8382-8395.
Amsden, B. (1999). An obstruction-scaling model for diffusion in homogeneous hydrogels. Macromolecules, 32, 874-879.

Cardoso, S. M., Ferreira, J. A., Mafra, I., Silva, A. M. S., \& Coimbra, M. A. (2007). Structural ripening-related changes of the arabinan-rich pectic polysaccharides from olive pulp cell walls. Journal of Agricultural and Food Chemistry, 55, 7124-7130.

Carvalho, J., Gonçalves, C., Gil, A. M., \& Gama, F. M. (2007). Production and characterization of a new dextrin based hydrogel. European Polymer Journal, 43, 3050-3059.

Ciucanu, I., \& Kerek, F. (1984). A simple and rapid method for permethylation of carbohydrates. Carbohydrate Research, 131, 209-217.

Dijk-Wolthuis, W. N. E., Hoogeboom, J. A. M., van Steenbergen, M. J., Tsang, S. K. Y., \& Hennink, W. E. (1997). Degradation and release behavior of dextran-based hydrogels. Macromolecules, 30, 4639-4645.

Dordick, J. S., Linhardt, R. J., \& Rethwisch, D. G. (1994). Chemical and biological catalysis to make swellable polymers. Chemical Technology, 7, 33-39.

Efentakis, M., \& Buckton, G. (2002). The effect of erosion and swelling on the dissolution of theophylline from low and high viscosity sodium alginate matrices. Pharmaceutical Development and Technology, 7, 69-77.

Han, J. H., Krochta, J. M., Kurth, M. J., \& Hsieh, Y.-L. (2000). Lactitol based poly(ether polyol) hydrogels for controlled-release chemical and drug delivery systems. Journal of Agricultural and Food Chemistry, 48(11), 5278-5282.

Hubbell, J. A. (1995). Biomaterials in tissue engineering. Biotechnology (Vol. 13, pp. 565-576). NY, USA.

Kane, J. B., Tompkins, R. G., Yarmush, M. L., \& Burke, J. F. (1996). In Biomaterials science: An introduction to materials in medicine (pp. 360-370). San Diego, USA: Academic Press.

Kanjickal, D. G., \& Lopina, S. T. (2004). Modeling of drug release from polymeric delivery systems. Critical Reviews in Therapeutic Drug Carrier Systems, 21, 345-386.

Lee, P. I. (1981). In Controlled release of pesticides and pharmaceuticals (pp. 39-48). New York, USA: Plenum Press.

Lévesque, S. G., Lima, R. M., \& Shoicheta, M. S. (2005). Macroporous interconnected dextran scaffolds of controlled porosity for tissue-engineering applications. Biomaterials, 26, 7436-7446.

Mafra, I., Lanza, B., Reis, A., Marsilio, V., Campestre, C., Angelis, M., et al. (2001) Effect of ripening on texture, microstructure and cell wall polysaccharide composition of olive fruit. Physiologia Plantarum, 111, 439-447.

Mason, M. N., Metters, A. T., Bowman, C. N., \& Anseth, K. S. (2001). Predicting controlled-release behaviour of degradable PLA- $b$-PEG- $b$-PLA hydrogels. Macromolecules, 34, 4630-4635.

McCulloch, I., \& Shalaby, S. W. (1998). In Tailored polymeric materials for controlled delivery systems. Washington, DC, USA: American Chemical Society.

Meyvis, T., Smedt, D. S., Stubbe, B., Hennink, W., \& Demeester, J. (2001). On the release of proteins from degrading dextran methacrylate hydrogels and the correlation with the rheologic properties of the hydrogels. Pharmaceutical Research, 18, 1593-1599.

Okano, T., \& Kikuchi, A. (2002). Pulsatile drug release control using hydrogels. Advanced Drug Delivery Reviews, 54, 53-77.

Park, H., \& Park, K. (1996). Hydrogels in bioapplications. In Hydrogels and biodegradable polymers for bioapplications (pp. 2-10). Washington, DC: Ottenbrite, American Chemical Society.

Peppas, N. A. (1996). In Biomaterials science: An introduction to materials in medicine (pp. 60-64). San Diego, USA: Academic Press.

Peppas, N. A., Bures, P., Leobandung, W., \& Ichikawa, H. (2000). Hydrogels in pharmaceutical formulations. European Journal of Pharmacology, 50 27-46.

Ramos, R., Carvalho, V., \& Gama, F. M. (2006). Novel hydrogel obtained by chitosan and dextrin-VA copolymerization. Biotechnology Letters, 28, 1279-1284.

Ratner, B. D. (2002). Reducing capsular thickness and enhancing angiogenesis around implant drug release systems. Journal of Controlled Release, 78, 211-218.

Rice, M. A., Sanchez-Adams, J., \& Anseth, K. S. (2006). Exogeneously triggered, enzymatic degradation of photopolymerized hydrogels with polycaprolactone subunits: Experimental observations and modelling of mass loss behaviour. Biomacromolecules, 7, 1968-1975.

Sujja-areevath, J., Munday, D. L., Cox, P. J., \& Khan, K. A. (1998). Relationship between swelling, erosion and drug release in hydrophilic natural gum mini-matrix formulations. European Journal of Pharmaceutical Science, 6, 207-217.

Tahara, K., Yamamoto, K., \& Nishihata, T. (1995). Overall mechanism behind matrix sustained release (SR) tablets prepared with hydroxypropyl methylcellulose 2910. Journal of Controlled Release, 35, 59-66.

Teixeira, J. A., Mota, M., \& Venâncio, A. (1994). Model identification and diffusion coefficients determination of glucose and malic acid in calcium alginate membranes. Chemical Engineering Journal, 56, B9-B14.

Vlugt-Wensink, K. D. K., Vlugt, T. J. H., Wim, J. W., Crommelin, D. J. A., Verrijk, R., \& Hennink, W. E. (2006). Modelling the release of proteins from degrading crosslinked dextran microspheres using kinetic Monte Carlo simulations. Journal of Controlled Release, 111, 117-127.

Vyavahare, N., \& Kohn, J. (1994). Photocrosslinked hydrogels based on copolymers of poly(ethylene glycol) and lysine. Journal of Polymer Science, 32, 1271-1281. 